expenses and 25 francs a day each during its sessions in Rome, or other fixed place of meeting.

The constitution of this Board is admirable, since it secures a fair representation of the leading scientific men of Italy. The Italian Government does not, it seems, refer such questions exclusively to one individual, but endeavours to obtain a consensus of the scientific opinion of the country.

Hôtel de la Ville, Florence

E. RAy LANKESTER

\section{Fabry's Comet and Barnard's Comet}

NoT having seen any mention of the rapid apparent growth of the tail of Fabry's comet, probably some of your readers are not aware to how great a length it extended. On April 26 occurred the first fine night after a very unusual series of overcast ones, and about 14 h. G.M.T. I was surprised to see the tail reaching up to, or at least to within $\mathbf{I}^{\circ}$ of, $\delta$ Cassiopeiæ, a distance of $38^{\circ}$ from the place given in the ephemeris for the nucleus, which was far below the horizon; and the tail would doubtless have been visible to a greater distance but for the brightness of the Milky Way. The following night, about Ioh., it reached at least up to the Cluster in Perseus, a distance also of $38^{\circ}$ from the predicted position of the nucleus; it was very narrow both nights. The next night, which was pretty fine, I failed to find any trace of the tail.

The principal tail of Barnard's comet is also very narrow : on May I its length was $4 \frac{1}{2}^{\circ}$, as seen with a pair of field-glasses. With the telescope this comet had also a faint tail $n f$, about 16 long, making an angle of $65^{\circ}$ or $70^{\circ}$ with the other.

$$
\begin{array}{ll}
\text { Sunderland, May } 7 & \text { T. W. BACKHouse }
\end{array}
$$

\section{"Pumice on the Cornish Coast"}

STEAMER-CINDERS, similar to those referred to by $\mathrm{Mr}$. Whitaker in NATURE for April 29 (p. 604), occur frequently on the Falmouth beaches; but as there seemed to me little probability of their being mistaken for pumice, I did not refer to the matter in my communication to your columns (April I5, p. 559).

Mr. Murray tells me that the pumice I found is felspathic, and that from its form and diminished buoyancy it had evidently been a long time in the water. The fragment was sent by him to $\mathrm{Mr}$. Whitaker, who at once recognised its true character and its distinction from the steamer-cinders observed by him on the Suffolk coast, one of which he sent to Mr. Murray to satisfy him as to their very evident source.

95, Albert Street, Regent's Park, N.W., May 8

\section{THE VELOCITY OF LIGHT}

I.

[A reinvestigation of this important constant has recently been published by Prof. Newcomb. Before we state his methods and results we think it well to reproduce the following admirable historical notice with which his monograph commences.-ED.]

WHEN it became clearly understood that vision was not an immediate perception of objects by the eye, but was produced by the passage of an entity called light from the object to the eye, the question of the time which might possibly be required for this passage became one of interest to physical investigators. The first proposal for an experimental investigation of this question is due to Galileo. ${ }^{1}$ He suggested that two observers, each holding a lantern, should be stationed at a distance apart, in sight of each other. Each should be supplied with a screen, by which he could, in a moment, cover or uncover his lantern. One observer should then uncover his lantern and the other uncover the other the moment he perceived the light from the first lantern. The interval which elapsed after the first uncovered his light, until he perceived the light of the second, would be the interval required for the light to go and come, plus the time required for the second observer to perceive the light and make the required movement. This experiment was tried by the Florentine Academy, and of course resulted in a

" Pcggendorff, Geschichte der Phy'sik, N. 402, where reference is made to he Saggi of the Florentine Academy. conclusion that the time required was insensible, since we now know that it was far below any interval that could have been detected by so rude a method.

It is, however, interesting to notice that, rude though this experiment was, the principle on which it was based is the same which underlies one of the most celebrated methods used in recent times for the attainment of the same object. Two very simple improvements which we might have imagined the Academicians to make in their experiments are these :-

Firstly, to dispense with the second observer, and in his place to erect a mirror, in which the first observer could see the image of his own lantern by reflection. The time required for the second observer to perceive the light and uncover his lantern would then have been eliminated from the problem. The interval sought would have been that between the moment at which the observer uncovered his lamp and the moment at which he perceived the reflection.

Secondly, to use the same screen with which he uncovered his own lamp, to cut off the returning ray from the distant mirror, and thus obviate the necessity of an uncertain estimate of the interval between his muscular effort in removing the screen and his perception of the return flash of light. If the image was perceived before he could cover his own eye with the screen removed from the lamp, it would show that the interval of passage was less than the time required to make a motion with the screen. This interval might have been reduced almost indefinitely by having both lines of sight as near together as possible.

Had these improvements been made, the Academicians would have had, in principle, Fizeau's method of measuring the velocity of light by the toothed wheel, a tooth being represented by the screens. To realise the principle more fully, the two lines of sight should have been rendered absolutely coincident by reflection through a telescope. It does not, however, appear that any effort to put the question to a severer test was made until the subject was approached from a different point of view. It was probably considered that the passage was absolutely instantaneous, or, at least, that the velocity was above all powers of measurement.

The subject was next approached from the astronomical side. In 1676 Roemer made his celebrated communication to the French Academy, claiming that observation of the eclipses of the first satellite of Jupiter did really prove that light required time to pass through the celestial spaces. ${ }^{1} \mathrm{He}$ found $\mathrm{I} \mathrm{Im}$. to be the time required for light to pass over a distance equal to the radius of the earth's orbit. Dominique Cassini, while admitting that the hypothesis of Roemer explained the observed inequality, contested its right to reception as an established theory, on the ground that the observed inequality might be a real one in the motion of the satellite itself. ${ }^{2}$

Continued observation showed that the time assigned by Roemer for the passage of light between the earth and sun, or "the light equation" as it is briefly called, was somewhat too great. In I 809 it was fixed by Delambre at $493^{\circ} 2 \mathrm{~s}$., from an immense number of observations of eclipses of Jupiter's satellites during the previous i 50 years. This number has been received as a definitive result with a degree of confidence not at all warranted. In 1875, Glasenapp, then of Pulkowa, from a discussion of all available eclipses of Jupiter's first satellite between r 848 and 1870 , showed that results between $496 \mathrm{~s}$. and $50 \mathrm{~s}$. could be obtained from different classes of these observations by different hypotheses. ${ }^{3}$

Paris Memoirs, tome i. p. 212, and tome x. p. 57

2 Ibid. tome viii. p. 47. Poggendorff (Geschichte der Physik, p. 656) quotes Maraldi as also contesting Roemer's explanation on the ground that a similar inequality should be found depend.ng on the position of Jupiter in his orbit. The ground here taken was quite correct, the only fallacy being the assumption that such an inequality did not exist.

3 This paper of Glasenapp's was published cnly in the Russian language as an inaugural dissertation, and in consequence has never become generally known. 